\title{
TEACHING AND LEARNING
}

\section{Using Checks for Understanding in Online Instruction}

\author{
CHLOE DUFOUR \\ University of Pittsburgh, Pittsburgh, PA \\ chd84@pitt.edu
}

When I was asked to offer library instruction over Zoom to a course that I had worked with in the past, I simply adjusted the learning activity I had done in person to be done virtually. This ended up being a mistake--the activity was reliant on using breakout rooms, a Zoom functionality that was not working that day. I quickly shifted how students would spend their time. They worked individually to brainstorm and then came back together to discuss. However, when I said, "Does anyone have any questions about anything?," I was met with turned-off cameras, silent mics, and no chats.

I wanted to open a dialogue with these students, and I could not. I did not have this issue in the past for several reasons. Being present, in person, meant I could see students' faces. I could walk around the room and talk with each group to ensure they were on task, and the process felt less removed. With online instruction, I needed to lower my expectations for spontaneous discussion. But I also needed to make sure they understood the information I was giving, so I took a cue from $\mathrm{K}-12$ teaching methods and used checks for understanding.

Checks for understanding are classroom assessment techniques where you stop and informally gather information from students to gauge their knowledge of the material you are covering. The intent is to use this information to inform how you present material (Fisher, 2014). It is common in K-12 education to plan for and incorporate checks for understanding directly into lessons, to ensure that they happen. While in higher education these checks do occur, they are not typically a part of the lesson plan. There is also literature on incorporating these techniques into library instruction (Bowles-Terry \& Kvenlid, 2015). An example for library instruction would be to open a session by asking if any students have ever been introduced to library resources before. If the response from the class is overwhelmingly that they have, then the librarian can adjust their lesson to potentially cover advanced searching techniques.

My next step is to incorporate these techniques into online library instruction. Technology can be used to assist here. Zoom comes with a built-in polling feature that can be used to ask a class what their past experience with the library has been. Mentimeter (https://www.mentimeter.com/) and NearPod (https://nearpod.com) allow instructors to integrate multiple choice questions into course content, then collect answers in their presentations. Spiral (https://spiral.ac) allows instructors to ask questions verbally and for students to submit responses from a device. While many of these tools are aimed at $\mathrm{K}-12$ audiences, it is worth using them in higher education to facilitate classroom assessment during library instruction. 
Ticker: The Academic Business Librarianship Review, 5:2 (2021)

http://dx.doi.org/10.3998/ticker.16481003.0005.205

(C)2021 Chloe Dufour

\section{References}

Bowles-Terry, M., \& Kvenild, C. (2015). Classroom assessment techniques for librarians. Chicago, IL: Association of College and Research Libraries.

Fisher, D., Frey, N. (2014). Checking for understanding: Formative assessment techniques for your classroom (2nd edition). Alexandria, VA: Association for Supervision \& Curriculum Development. 